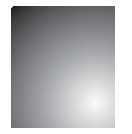

\section{Trabalho Voluntário: motivos para sua realização}

\author{
Voluntary Work: reasons for its accomplishment
}

Washington José de Souza

Professor do Programa de Pós-Graduação em Administração, Universidade Federal do Rio Grande do Norte - Natal - RN, Brasil.

E-mail:wsouza@ufrnet.br

Jássio Pereira de Medeiros

Professor do Instituto Federal de Educação, Ciência e Tecnologia do Rio Grande do Norte - Natal - RN, Brasil. E-mail: jassio.pereira@ ifrn.edu.br

\section{Resumo}

Numa economia de mercado com problemas estruturais, o setor social torna-se alternativa de resposta à dinâmica da acumulação do capital. Fundado no entendimento de que a decisão espontânea para o exercício do trabalho voluntário envolve motivos diversos, o presente texto objetiva desenvolver uma tipologia para essa atividade. $\mathrm{O}$ trabalho voluntário congrega categorias de motivos altruístas, de interesse próprio e de sociabilidade, mediados por ideais religiosos, afetivos/aflitivos, resultantes de sentimentos de culpa ou de obrigação para com o outro, ou, ainda, de sentimentos de responsabilidade. Não obstante a esse componente político-ideológico, o trabalho voluntário ganha espaço no meio social e, por essa razão, cabe aos estudiosos da Gestão Social, a tarefa de compreender e sistematizar conteúdos. Esses conteúdos estariam associados a valores como abnegação, dedicação, amizade, aprendizagem e ambição.

Palavras-chave: Trabalho Voluntário. Gestão Social. Voluntariado Empresarial. Terceiro Setor.

\section{Abstract}

In a market economy with structural problems, the social sector becomes alternative of reply the dynamics of the capital's accumulation. Established in the agreement of that the spontaneous decision for the exercise of the voluntary work involves diverse reasons, the present paper objective to the development a typology for this activity. The voluntary work congregates categories of altruistic reasons, of proper interest and of sociability, mediated for religious ideas, affective or distressing, resultant of the guilt feelings or obligation to the other, or, still, of responsibility feelings. Not so far these politician-ideological components, the voluntary work gaining spaces in social environment and, therefore, belong to the studious of the Social Management, the task to understand and systemize contents. These contents would be associates, therefore, the values as self-denial; devotion; friendship, learning and ambition.

Key words: Voluntary Work. Social Management. Enterprise Voluntaries. Third Sector. 


\section{INTRODUÇÃO}

A economia mundial, especialmente após a Segunda Guerra, vem atravessando sucessivas transformações que se manifestam, neste início de milênio, em contradições e mudanças estruturais e conjunturais na sociedade e no Estado. Transformações determinadas por novas dinâmicas de acumulação do capital e de concorrência intercapitalista, aliadas a um conjunto de propostas neoliberais econômicas e de gestão pública, vêm provocando sucessivas reformas no aparelho do Estado o que o torna, progressivamente, insuficiente no atendimento às demandas sociais. Por outro lado, novas tecnologias transformam o setor produtivo, ampliando o desemprego e o número de pessoas dependentes do sistema previdenciário ao tempo em que é reduzido o volume da população economicamente ativa contribuinte para o sistema. Tais dinâmicas comprimem o sistema previdenciário e, do ponto de vista neoliberal, justificam reformas que flexibilizam o mercado de trabalho e as relações de trabalho fazendo proliferar, sob formas organizacionais diversas, iniciativas de desenvolvimento fundadas na solidariedade e na cooperação entre atores sociais, o que inclui arranjos e redes de trabalho voluntário, cooperativo e associativo $e$ instituições assistenciais, dentre outros.

Surgem, assim, novos desafios aos processos da intervenção social que visam à amenização dos efeitos trazidos pela desigualdade, pelo desemprego e exclusão social crescentes. Dessa forma, em uma situação de economia de mercado com problemas estruturais, o setor social, torna-se alternativa de resposta à dinâmica da acumulação do capital, tanto quando responde às ausências do Estado, quanto no instante em que oportuniza espaços sociais de ocupação e de geração de renda. O desenvolvimento das organizações sociais explica, em parte, o avanço de parcerias e alianças entre grupos diversos na captação de recursos junto ao mercado, a governos e comunidades no intuito de viabilizar a realização de atividades que não estariam sendo desenvolvidas pelo Estado nem tampouco pelo setor privado. É nesse cenário que o trabalho voluntário assume, progressivamente, importante papel nas sociedades contemporâneas.

Em maior ou menor grau, as organizações voluntárias fazem parte da trajetória humana no atendimento, por exemplo, as situações de desigualdades, de calamidades e de formação. No início, estavam vinculadas, por um lado, a organizações religiosas e étnicas, na perspectiva da formação e da conquista de direitos e na disseminação da noção de caridade. Por outro lado, proliferaram a partir de lideranças carismáticas, na constituição de exércitos que se destinavam à conquista, ao domínio ou à proteção de populações sob a ameaça. Esse último foi o caso da articulação dos exércitos voluntários na Inglaterra durante o período das conquistas napoleônicas na Europa. (GEE, 2003)

Fundado, pois, no entendimento de que a decisão espontânea para o exercício do trabalho voluntário envolve motivos diversos, o presente texto objetiva o apontamento de motivos para essa atividade. O texto parte de definições de ocupação e trabalho (esse associado ao trabalho na economia capitalista) para, na sequência, abordar uma hierarquia em cinco níveis para o trabalho voluntário, que adota como eixo o grau de altruísmo/egoísmo presente na decisão. Ao final, são indicadas limitações ao exercício aqui realizado $e$ elaborada uma crítica ao crescimento do trabalho voluntário considerando o contexto atual de acumulação do capital e de reformas neoliberais do Estado.

\section{Ocupação, trabalho e Trabalho VoluntáRIO}

A discussão em torno da natureza e da diversidade do trabalho humano, e suas interfaces com o trabalho solidário, é elaborada aqui tomando como referência o debate de Marx (1983 e 1987), a respeito do trabalho, e de Ramos (1989), no campo organizacional.

Em sentido genérico, trabalho é qualquer atividade por meio da qual o homem transforma a natureza das coisas e de semelhantes e a si mesmo, podendo assumir, portanto, caráter positivo, pela via da autonomia e da autorrealização, ou negativo, ao implicar em sofrimento e alienação. Em sentido negativo, como trabalho alienado, sob a ótica do sistema de produção capitalista, o homem é transformado em mercadoria, em um ser mental e fisicamente desumanizado, passando a existir, então, a produção da atividade humana exclusivamente como trabalho; isto é, uma atividade estranha em si mesma, ao homem e à natureza, e, portanto, estranha à consciência e à realização da vida humana (MARX, 1983). Dessa forma, o trabalho 
como atividade prática negativa é um trabalho unidimensional, reduzido à dimensão da lucratividade, à produção de valores de troca, à mercadoria, não sendo esta, contudo, a única natureza do trabalho. Por isso, Marx (1983) discute o duplo caráter do trabalho e da mercadoria.

A riqueza capitalista configura-se em acumulação de mercadorias que, essencialmente, satisfazem necessidades humanas. A utilidade da mercadoria atribui a ela um valor de uso, ao passo que o valor de troca revela-se, inicialmente, na relação quantitativa entre valores de uso de espécies diferentes, na proporção em que se trocam. O valor de uso é determinado pelas propriedades materialmente inerentes à mercadoria, não dependendo da quantidade de trabalho empregado na obtenção de suas qualidades úteis. Esse valor realiza-se, portanto, com a utilização ou o consumo, satisfazendo necessidades. Como valores-de-uso as mercadorias aparecem, pois, com diferentes qualidades.

A mercadoria, ao aparecer com um duplo caráter, fornece, também ao trabalho, duas formas de manifestações. No conjunto dos valores de uso diferentes, ou das mercadorias materialmente distintas, manifesta-se um conjunto correspondente de trabalhos úteis diversos. O valor de uso aparece, então, como resultado da atividade produtiva destinada a um fim específico. O trabalho, neste caso, é indispensável à existência do homem, surgindo como necessidade natural de intercâmbio material entre o homem e a natureza, contribuindo para a preservação da vida. É esse, pois, o sentido positivo do trabalho humano em Marx (1987).

Resume Marx (1987) que o trabalho contido em uma mercadoria, do ponto de vista do valor de uso, só interessa qualitativamente, enquanto do ponto de vista da grandeza de valor (valor de troca), só interessa quantitativamente, quando interpretado como trabalho humano puro e simples. Ou seja, todo trabalho é dispêndio de força humana, no sentido fisiológico, e, nessa qualidade de trabalho humano igual e abstrato, cria o valor (valor de troca) das mercadorias. Por outro lado, é também dispêndio de força humana de trabalho, sob a forma específica, para um determinado fim, $e$, nessa qualidade de trabalho útil e concreto, produz valores de uso. É em virtude desse entendimento que em todas as sociedades pré-mercado, dotadas de algum grau de diferenciação social, existiu sempre uma distinção entre atividades ou ocupações superiores e inferiores, do ponto de vista de uma classificação existencial (RAMOS, 1989). As atividades de categorização superior são exercidas pelo indivíduo de forma autônoma, de modo a satisfazer o desejo de realização pessoal, respondendo a necessidades subjetivamente delineadas. De outra forma, as atividades que não alcançam esse nível superior são, na maior parte dos casos, estabelecidas por necessidades objetivas exteriores ao indivíduo (o mercado) e, portanto, aparecem desvinculadas de decisões e de expectativas pessoais, sendo esse o caso do trabalho capitalista.

Desse modo, o trabalho seria a prática de um esforço subordinado às necessidades objetivas inerentes ao processo de produção em si, assumindo, o sistema de mercado, condições excepcionais para estabelecer um comando sobre a vida social das pessoas. Por isso, o trabalho é dividido, de maneira que quanto mais o indivíduo se adapte a certas funções mecânicas, melhores se tornam os resultados práticos obtidos. Não se espera, portanto, que o homem se ocupe em algo que lhe traga prazer ou preencha uma necessidade própria, mas, sim, que ele trabalhe. A essa concepção abstrata e genérica de trabalho, que cria valor de troca (MARX, 1987) e que inibe a possibilidade de ocupação do homem em algo que proporcione realização e autonomia (RAMOS, 1989), aparece atrelado o conceito de emprego, próprio das relações capitalistas de trabalho e do sistema social "economia". Nesse sistema, o emprego se traduz em posto de trabalho formal junto a uma organização ou a uma pessoa física, no escopo do mercado, com efeitos alienantes na vida humana.

O emprego, instituto das relações de mercado, reflete uma face negativa do trabalho em Marx (1987), por denegrir a condição humana, determinando um preço médio que o indivíduo deve receber pela atividade realizada, o que é suficiente para garantir o estritamente necessário à continuidade da sua existência.

De acordo com Ramos (1989), ocupação é prática de esforços livremente produzidos pelo indivíduo em busca de realização pessoal, estando, portanto, localizada a uma face positiva do trabalho humano, uma vez determinada por objetivo autonomamente escolhido, gerador de prazer, que amplia e promove a vida. É plausível aceitar que essa face positiva do trabalho humano vem se ampliando, nos dias atuais, sob estratégias diversas de atividades sociais coletivas articuladas em organizações voluntárias, assistenciais, 
associativas e cooperativas genericamente tratadas por Ramos (1989) como fenonomias e isonomias.

A fenonomia é um sistema social de caráter esporádico, iniciado e dirigido por um indivíduo, ou por um pequeno grupo, consistindo em um ambiente necessário às pessoas para a liberação da criatividade, sob plena autonomia. Seus membros empenham-se apenas em obras automotivadas e, apesar de interessados na singularidade, membros da fenonomia têm consciência social. Detectam-se como exemplos de fenonomia as oficinas de arte, os grupos culturais, os inventores e as pessoas que trabalham por conta própria em atividades que consideram autogratificantes.

A isonomia, por sua vez, pode ser definida como um contexto em que todos os membros de uma organização são iguais e conquistam a realização independentemente de prescrições impostas. Nesse tipo de sistema social, as atividades realizadas são desenvolvidas como vocações, não como empregos, sendo por meio de relações primárias que se estabelece a eficácia organizacional, o que implica dizer que, caso a isonomia aumente de tamanho além de determinado ponto ideal, declinará até se transformar em uma democracia, oligarquia ou burocracia. Apesar do entendimento de que não há organização completamente isonômica, uma vez que o conceito serve apenas como propósito heurístico, é possível destacar exemplos de ambientes com elevado grau de isonomia como associações de pais, de professores e de estudantes; associações comunitárias; organizações de trabalho cooperativo; dentre outros.

Em virtude dessas características peculiares, tanto as fenonomias quanto as isonomias não são espaços em que o indivíduo deverá buscar bem-estar traduzido em ganhos materiais, são, sim, espaços para a autorrealização pela via da efetivação de atividades autogratificante, como é o caso, dentre outras, do trabalho voluntário.

Desde os escritos da Escola Sociotécnica, em meados dos anos de 1950, pesquisadores dedicam esforços para compreender o significado e os sentidos do trabalho para as pessoas e, por essa razão, vários estudos, em diversos campos do conhecimento e ainda que em perspectivas teóricas antagônicas, mostram como o trabalho ocupa espaço peculiar nas sociedades industrializadas. (ANTUNES, 1995; 1999; BAUMAN,
1998; BECK, 1999; CASTELLS, 1999; HARVEY, 1993; RIFKIN, 1995; SENNET, 1999; SCHAFF, 1995)

Os estudos do Grupo Meaning of Work (MOW) e da Escola Sociotécnica abordam seis características essenciais para que um trabalho represente sentido positivo para o seu executor: o trabalho deve ser eficiente e produzir um resultado útil para a sociedade, isto é, o trabalho que faz sentido é feito com efetividade e leva a alguma coisa; deve proporcionar prazer na realização da tarefa, de modo a ser satisfatório em si, resolver problemas e usar o talento e o potencial de seus executores; deve permitir autonomia; ser fonte de relações humanas satisfatórias, o que inclui encontrar pessoas de qualidade e desenvolver laços de afeição; manter as pessoas ocupadas, preenchendo o tempo da vida, evitando o vazio e a ansiedade e ser moralmente aceitável, ou seja, deve ser feito de maneira socialmente responsável. Essas características aproximam-se de valores discutidos por Ramos (1989) acerca da "ocupação" e da razão que conduz os indivíduos a trabalhos com tais peculiaridades.

Em maior ou menor grau, as organizações voluntárias estiveram presentes nas comunidades. No início, elas eram, em sua maioria, vinculadas às organizações religiosas e étnicas. A noção de caridade, incentivada por quase todas as religióes, está fortemente relacionada a esse tipo de atividade.

Para Wuthnow (1991), o papel da religião no setor voluntário é uma peça importante para entender as variações históricas no desenvolvimento do setor social e por que em alguns casos ele é forte, e em outros, ausente. Entretanto, Coelho (2000) entende que a interpretação de Wuthnow vincula muito estreitamente o desenvolvimento desse setor à pluralidade religiosa do país. Assim, a autora argumenta que a sua estruturação é, na verdade, o resultado de uma combinação de fatores específicos de cada país, entrando nesse cômputo a formação socioeconômica, as opções políticas e a cultura local. Corroborando com Coelho (2000), Teodósio (2002) coloca que o voluntariado é percebido como sinônimo automático de cidadania, quando na verdade a realidade sociopolítica do nascimento do voluntariado em países como os Estados Unidos, marcadamente uma nação cujo associativismo é uma instituição social, se faz distante de países como o Brasil. No cenário brasileiro, o voluntariado muitas vezes não imprime uma mudança significativa nos 
padrões assistencialistas e clientelistas da oferta de políticas públicas.

Focando o indivíduo, a ideia de voluntariado presume, até certo ponto, uma renúncia ao próprio interesse, em favor do interesse, do bem-estar e do progresso da coletividade. Os motivos que levam o indivíduo a atuar como voluntário numa organização são diferentes daqueles que o impulsionam para a atividade remunerada, normalmente exercida no mercado. Aqui, Teodósio (2001) esclarece que a lógica do trabalho voluntário "não ser remunerado" tem sido entendida como "não remunerado monetariamente", pois há outras formas de retribuição ou pagamento esperadas por esse trabalho, como de ordem emocional, ideológica, simbólica ou profissional. Nesses casos, o voluntário receberia, por exemplo, contato humano e convivência com outras pessoas, resultando em novas oportunidades de conhecimento e de crescimento pessoal.

Trata-se de ação espontânea e não remunerada exercida por pessoas que, pelos mais diferentes motivos (religiosos, familiares, políticos ou simplesmente pessoais), colocam à disposição seu tempo e seu trabalho em prol da melhoria da sociedade em que vivem. Garay (2001) menciona a realização, a satisfação em servir e a possibilidade de uma contribuição clara como os principais elementos que dão sentido ao trabalho voluntário no setor social. Assim, o vínculo a um ideal ou missão e a importância do valor social têm sido relatados como elementos fundamentais nesse tipo de trabalho, sendo comum a referência de que é imprescindível que o voluntário tenha verdadeiro interesse pelo trabalho desenvolvido e entusiasmo pelos objetivos do projeto ou instituição. Atualmente, a quantidade de voluntários que atuam em Organizações não Governamentais é da ordem de 20 milhões de pessoas. Ou seja, um, em cada cinco brasileiros, com idade entre 15 e 60 anos, está dedicando algumas horas do dia para ajudar alguém.

As organizações voluntárias estão inseridas dentro do campo de atuação que Andion (2001) considera como organizações de economia solidária, as quais, de acordo com Serva (1997), comportam organizações que realizam atividades econômicas marcadas, sobretudo, pela predominância do princípio da reciprocidade, contrariamente à economia de mercado, na qual predomina o intercâmbio comercial. Essas organizações são criadas a partir da mobilização da sociedade civil e compreende associações civis de caráter público, as organizações comunitárias, as organizações voluntárias $e$ as Organizações não Governamentais de atuação social direta.

A ideia do trabalho voluntário pressupõe, até certo ponto, renúncia ao benefício próprio, em favor do interesse, do bem-estar e do progresso do outro $e$ de coletividades. Os motivos que levam indivíduos a atuar como voluntário são diferentes daqueles que os impulsionam a realizar atividade remunerada, por se tratar de doar e receber contatos humanos, convivendo com outras pessoas sob o contrato social espontâneo - o que resulta em novas oportunidades de conhecimento e de crescimento pessoal - ao invés da relação contratual formal inerente ao trabalho de natureza econômica.

Para Dohme (2001, p. 17), voluntário é o sujeito "[...] que doa o seu trabalho, suas potencialidades e talentos em uma função que a desafia e gratifica em prol da realização de uma ação de natureza social". De maneira mais ampla, Cohen (1964) vê o voluntário como sujeito que age de forma não compulsória e não remunerada, para cumprir papel de cidadão.

Ser voluntário é, de acordo com Domeneghetti (2002), doar-se a uma causa, é ter no coração o dom do amor, o dom da caridade, da solidariedade, enfim, o dom de servir. É ter consciência de estar prestando um serviço à sociedade, ao seu próximo, cumprindo o papel de cidadão consciente.

O trabalho voluntário, diferentemente do trabalho formal presente nas organizações capitalistas, tem sido definido como o esforço oferecido espontaneamente, ou a pedido, sem remuneração, por qualquer pessoa que deseja colaborar por amor, benevolência, afeto, compreensão e responsabilidade em organismos que trabalham em favor do bem-estar coletivo. (GARAY, 2001)

O voluntário, por sua vez, de acordo com a Lei n. 9.608/98, que regulamenta a atividade voluntária no Brasil, é

[...] a pessoa física que realiza atividade não remunerada junto à entidade pública de qualquer natureza ou à instituição privada de fins não lucrativos, que tenha objetivos cívicos, culturais, educacionais, científicos, recreativos ou de assistência social, inclusive mutualidade. (PORTAL DO VOLUNTÁRIO, 2006) 
O trabalho voluntário é, assim, uma ação espontânea e não remunerada exercida por pessoas que, por diferentes motivos, colocam à disposição do outro tempo e trabalho em prol da melhoria da sociedade em que vivem.

Na acepção de Hudson (1999), o setor voluntário oferece três contribuições importantes para a sociedade:

a) representação, por contribuir para o desenvolvimento de políticas públicas e para os processos de integração e coesão social;

b) inovação, por incorporar ações que transformam o meio social, desenvolvendo sujeitos e comunidades; $e$

c) cidadania, por ser realizada a partir de ações de natureza informal e, mesmo assim, sob elevado grau de eficiência e eficácia.

$\mathrm{O}$ voluntariado vem ganhando força, aliado à promoção da cidadania. Há, por conseguinte, maior participação de pessoas, que se mobilizam com o propósito de ajudar ao próximo e fazer algo para amenizar mazelas socioeconômicas.

Em 2001, as ações no Brasil, de incentivo ao trabalho voluntário, intensificaram-se em virtude do Ano Internacional do Voluntariado, designado pela Organização das Nações Unidas (ONU). Por intermédio da resolução de 1997. A Resolução reconheceu a valiosa participação dos voluntários, incluindo as formas tradicionais de apoio mútuo e de autoajuda, na prestação de serviços e em outras formas de participação cívica, para o desenvolvimento econômico e social em benefício da sociedade em seu conjunto, comunidades ou indivíduos. Segundo Evangelista (2002), a ONU entende que o voluntariado é um componente importante a toda estratégia encaminhada à redução da pobreza, ao desenvolvimento sustentável e à integração social, em particular mediante a superação da exclusão e da discriminação social.

O que gera disposição para o trabalho voluntário é o sentimento altruísta, mas, até mesmo sem se dar conta, o voluntário espera usufruir algo, ainda que não seja concreto ou material. Pode-se afirmar que as pessoas se apresentam como voluntárias a fim de conseguir satisfação pela participação em um grupo; o que quer dizer que elas sentem necessidade de fazer parte de objetivos e de significados mais amplos da vida grupal, para obter a satisfação decorrente da dependência, da afeição, da situação social e da realização criadora. (COHEN, 1964)

O trabalho não é meramente um esforço que alguém realiza por dinheiro, mas, sim, uma atividade que produz algo com valor para outras pessoas (KONDO, 1989). Dessa forma, a decisão de executar um trabalho voluntário pode estar relacionada a expectativas como fazer diferença, usar habilidades, desenvolver-se pessoalmente, buscar satisfação por fazer parte de um grupo, ou, ainda, estar relacionada à identificação pessoal com a causa. (DOHME, 2001)

Outros atributos podem ser identificados como fatores que realçam o trabalho exercido pelo voluntário: o trabalho é exercido sob total adesão aos fins propostos; o voluntário trabalha em algo que gosta e que escolheu; o voluntário acrescenta amor ao trabalho que desenvolve (DOHME, 2001). O voluntário sente-se motivado quando pode contribuir para a diminuição do sofrimento ou das injustiças ou quando traz alegria ou contribui para a autossuficiência de outras pessoas, sentindo-se como agente construtor de comunidade, ou, ainda, quando o trabalho realizado fortalece a visão pessoal de mundo, permitindo difundir valores individuais.

Dohme (2001) cita os seguintes motivos de adesão ao trabalho voluntário:

a) atingir objetivos sociais, pois, o voluntário é aquele que, além de objetivos pessoais, tem visão própria da realidade social que o circunda e projeta objetivos para a comunidade;

b) ter uma participação efetiva na obtenção de objetivos sociais; $e$

c) buscar a aceitação de um grupo e harmonia.

O trabalho voluntário parte, portanto, de motivos que impulsionam indivíduos a fazer algo pelo próximo, a estar disposto para se expor a situações desafiantes, que não proporcionarão retorno financeiro, mas, sim, reconhecimento, agradecimento e sentimento de que o trabalho que está sendo realizado é útil, tem valor para alguém e interfere positivamente na sociedade. 


\section{Trabalho Voluntário: delineando MOTIVOS PARA A ATUAÇÃo}

Pesquisa realizada em 2001 pelo instituto Datafolha, em 127 municípios de todos os estados brasileiros, com 2.830 entrevistados, mostrava que, dos entrevistados, $41 \%$ se diziam muito e $34 \%$ um pouco dispostos a trabalhar como voluntários (AZEVEDO, 2007). Em seguida, a autora aponta como possíveis motivações para atuar no trabalho voluntário, o desejo de melhorar a comunidade, promover uma causa ou auxiliar pessoas a quem sequer se conhece, ou seja, uma ação contrária à existência de injustiças e de desigualdades. Essas ações recebem os nomes de altruísmo e/ou solidariedade, e são muitas vezes apontadas como motivadoras do voluntariado.

É fato, pois, que o trabalho voluntário congrega categorias de motivos altruístas, de interesse próprio e de sociabilidade, mediados por ideais religiosos, afetivos ou aflitivos, resultantes de sentimentos de culpa ou de obrigação para com o outro, ou, ainda, de sentimentos de responsabilidade. McCurley e Lynch (1998) sintetizaram os motivos do trabalho voluntário em três categorias, listando possíveis alegações pessoais para o engajamento (Quadro 1).

Mostyn (1993), por sua vez, esboçou cinco categorias de organizações voluntárias: altruísta; para ajudar pessoas em situação de aflição; para fornecer ajuda aos menos afortunados; para melhorar a sociedade; por interesse próprio. A autora relaciona tais concepções a tipos específicos de organizações voluntárias.

\begin{tabular}{|c|c|}
\hline $\begin{array}{c}\text { Categoria do } \\
\text { motivo }\end{array}$ & AlEgAÇÕES SUBJETIVAS POSSÍvEIS \\
\hline \multirow{6}{*}{ Altruísta } & Ajudar aos outros \\
\hline & $\begin{array}{l}\text { Obrigação de retribuir } \\
\text { por algo recebido }\end{array}$ \\
\hline & Dever cívico \\
\hline & Convicção religiosa \\
\hline & Fazer uma diferença no mundo \\
\hline & Crença na causa \\
\hline \multirow{3}{*}{ Interesse próprio } & Adquirir experiência \\
\hline & Desenvolver novas habilidades \\
\hline & Constituir amizades \\
\hline
\end{tabular}

Quadro 1: Motivos subjetivos para o trabalho voluntário Fonte: Adaptado de McCurley e Lynch (1998)

\begin{tabular}{|l|l|}
\hline & Causar boa impressão a alguém \\
\hline Interesse próprio & Exir-se importante e útil \\
\hline & $\begin{array}{l}\text { Experimentar novos estilos } \\
\text { de vida e culturas }\end{array}$ \\
\hline Prazer e alegria \\
\hline Aproximar a família \\
\hline Familiar & $\begin{array}{l}\text { Servir de exemplo } \\
\text { Benefício e retorno próprios }\end{array}$ \\
\hline $\begin{array}{l}\text { Retribuir algo recebido por } \\
\text { membro da família }\end{array}$
\end{tabular}

Quadro 1: Motivos subjetivos para o trabalho voluntário Fonte: Adaptado de McCurley e Lynch (1998)

A leitura conjunta dessas duas categorizações permite o esboço de uma Hierarquia do Trabalho Voluntário, por nível de altivez da ação, relacionando as atitudes de sujeitos ao ato voluntário. Numa Hierarquia de 5As seriam contemplados os seguintes níveis:

Nível I - Altruísta: retrata a percepção subjetiva de autossacrifício por parte do voluntário, envolvendo risco, insalubridade e periculosidade, sob a perspectiva da consciência de espécie e de questionamento em torno das condições gerais de vida de seres humanos.

Nível II - Afetivo: reúne motivos relativos ao sentimento de auxílio a sujeitos e comunidades em situações de exceção, via fornecimento de apoio direto aos menos aptos e prósperos como idosos, crianças, desabilitados e pacientes em hospitais, estando o voluntário interessado no resgate da cidadania.

Nível III - Amigável: contempla motivos vinculados à avaliação subjetiva de contribuição para o bem-estar social, e de desafortunados em particular, sob uma perspectiva amistosa, em que o voluntário se sente compartilhando algo próprio com alguém.

Nível IV - Ajustado: reúne motivos de uma forma específica de aprimoramento social não centrada em temas cruciais ou aflitivos, mas que, de alguma forma, transmite ao voluntário a sensação de estar, simultaneamente, promovendo a si próprio e a vida do receptor. 
Nível V - Ajuizado: congrega motivos centrados na sensação de privilégios, de status e de proteção, estando o voluntário interessado na construção $e$ na projeção da autoimagem e da promoção pessoal com os indivíduos e as coletividades.

Não apenas motivos subjetivos distintos estão vinculados à tipologia do trabalho voluntário, mas, graus diferenciados e complementares de racionalidade substantiva e instrumental, conforme sugere a Figura 1.

A ação racional substantiva, segundo Serva (1997, p. 22), é orientada de acordo com duas dimensões:

[...] dimensão individual - refere-se à auto-realização que gera potencialidades e satisfação; dimensão grupal - refere-se ao entendimento, nas direções da responsabilidade e satisfação sociais. Em contrapartida, a ação racional instrumental é uma ação baseada no cálculo, orientada para o alcance de metas técnicas, através da maximização de recursos disponíveis.

No par weberiano de racionalidade, ações que caracterizam a racionalidade instrumental ocorrem a partir da ênfase nos fins, no cálculo, com o deliberado propósito de maximizar resultados. De outra forma, ações fundadas na racionalidade substantiva relacionam-se ao julgamento ético, orientadas por valores. (RAMOS, 1989)
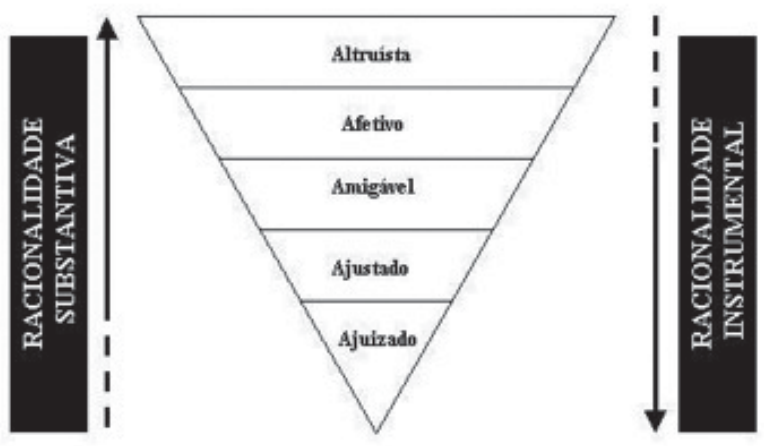

Figura 1: Diagrama da Hierarquia do Trabalho Voluntário Fonte: Adaptada de Mostyn (1993)

No diagrama da Figura 1 fica implícito o entendimento de que em toda e qualquer decisão racional graus diferenciados de racionalidade substantiva, ou instrumental, subsistem ao lado de graus complementares de racionalidade instrumental, ou substantiva. Assim, mesmo quando se advoga que o voluntário
Altruísta possui elevado compromisso com a promoção do bem-estar da humanidade, há de se considerar que a decisão está igualmente pautada em algum tipo de interesse individual para o engajamento cívico. $\mathrm{Na}$ outra extremidade, mesmo quando se advoga que no Nível do Trabalho Voluntário Ajuizado é elevada a presença da racionalidade instrumental, há de se considerar que a decisão racional da doação ao outro envolve algum grau de respeito, de envolvimento $e$ de consideração ao Ser, atestando valores próprios à natureza humana.

O Quadro 2 sintetiza esforço teórico para demarcação de motivos para o trabalho voluntário, demandando, contudo, averiguação de pertinência empírica.

\begin{tabular}{|l|l|l|l|}
\hline Tipo & Domínio & $\begin{array}{c}\text { VAloR } \\
\text { ATRIBuído }\end{array}$ & $\begin{array}{c}\text { QuESTão } \\
\text { CENTRAL }\end{array}$ \\
\hline Altruísta & $\begin{array}{l}\text { Condição } \\
\text { humana }\end{array}$ & Abnegação & $\begin{array}{l}\text { Como posso } \\
\text { contribuir com } \\
\text { a humanidade? }\end{array}$ \\
\hline Afetivo & $\begin{array}{l}\text { Coletivi- } \\
\text { dades }\end{array}$ & Dedicação & $\begin{array}{l}\text { Como posso } \\
\text { promover } \\
\text { cidadania? }\end{array}$ \\
\hline Amigável & $\begin{array}{l}\text { Grupos } \\
\text { sociais }\end{array}$ & Amizade & $\begin{array}{l}\text { O que tenho a } \\
\text { compartilhar? }\end{array}$ \\
\hline Ajustado & $\begin{array}{l}\text { Eu e os } \\
\text { outros }\end{array}$ & $\begin{array}{l}\text { Aprendi- } \\
\text { zagem }\end{array}$ & $\begin{array}{l}\text { O que aprendo } \\
\text { com isso? }\end{array}$ \\
\hline Ajuizado & Eu & Ambição & $\begin{array}{l}\text { O que ganho } \\
\text { com isso? }\end{array}$ \\
\hline
\end{tabular}

Quadro 2: Síntese da tipologia do trabalho voluntário Fonte: Adaptado de Mostyn (1993)

\section{No Nível do Trabalho Voluntário Altruísta} é factível julgar que a decisão aparece fortemente relacionada ao desejo de promover o bem-estar, por convicção política ou religiosa, mediante doação pessoal à prática e à socialização de iniciativas que atestam qualidades humanas superiores. No Nível do Trabalho Voluntário Afetivo, a decisão aparece pautada no (re)encontro com o coletivo. Para o voluntário, estar junto e fazer o bem aos outros transmite a sensação de dever cumprido, de responsabilidade. No Nível do Trabalho Voluntário Amigável, a decisão está vinculada à constituição e ao desenvolvimento de redes de sujeitos em situação similar, estando o voluntário interessado em compartilhar valores e em fortalecer elos grupais próximos a espaços situacionais que ele 
vivencia ou que vivenciou. No Nível do Trabalho Voluntário Ajustado, a decisão está fundada na busca de competências e de habilidades específicas, estando o voluntário interessado no autodesenvolvimento, pela via da ação social, sob o reconhecimento de status privilegiado. No Trabalho Voluntário Ajuizado, o cálculo é fator preponderante, estando a ação vinculada à perspectiva da autoproteção, mediadas pela ideia da obtenção e/ou preservação de vantagens próprias, ainda que secundariamente vinculadas ao coletivo.

\section{Considerações Finais}

A relevância que, nos dias atuais, assume o trabalho voluntário no meio social, na mídia e até mesmo no mundo dos negócios - mediante o chamado voluntariado empresarial - exige de militantes, de estudiosos e de pesquisadores do campo da Gestão Social acuidade no trato do tema. Trata-se de uma atividade contraditória nos meandros da economia capitalista, uma vez que se constitui em doação individual de trabalho dentro de um modelo econômico que se constitui mercadoria que sujeitos não capitalistas possuem para negociar no mercado e garantir a sobrevivência. Como doar trabalho em uma sociedade que compra e paga trabalho como outra mercadoria qualquer? A discussão desse ingrediente político não deve ser desconsiderada, pelo fato de que a realização de trabalho não pago, voluntário, gratuito, em uma sociedade capitalista, que contrata, compra e paga por trabalho realizado, se torna algo cômodo aos detentores do capital - contribuindo para a concentração de renda - e ao Estado, que passa a restringir a intervenção social reguladora.

Não obstante a esse componente político-ideológi$\mathrm{co}$ - que deve se fazer presente no universo do voluntariado - é fato que o trabalho voluntário vem ganhando crescentes espaços no meio social $e$, por essa razão, o presente texto delineia os motivos para essa atividade, partindo do pressuposto de que ela se explica e se manifesta sob uma diversidade de motivações e de interesses.

Os contornos atribuídos ao trabalho voluntário representam, aqui, ideias genéricas cuja manifestação empírica aparece mediada por elementos próximos. São, assim, categorias heurísticas, conforme reportadas por Serva (1997) quando ele descreveu a manifestação empírica de elementos de racionalidade. Na condição de conjuntos teóricos, tipos, domínios e valores atribuídos são válidos à designação subjetiva de graus diferenciados de nobreza à ação, sendo essa a perspectiva em que a presente proposta encontra suporte.

\section{REFERÊNCIAS}

ANDION, Carolina. As particularidades da gestão em organizações da economia solidária. In: XXV Encontro Nacional dos Programas de Pós-Graduação em Administração - ENANPAD, 2001, Campinas/ SP.

Anais... Campinas/SP: ANPAD, 2001.

ANTUNES, R. Adeus ao trabalho? Ensaios sobre as metamorfoses e a centralidade do mundo do trabalho. Campinas: Cortez, 1995.

ANTUNES, R. Os sentidos do trabalho: Ensaios sobre a afirmação e a negação do trabalho. São Paulo: Boitempo, 1999.

AZEVEDO, Denise. Voluntariado corporativo: motivações para o trabalho voluntário. Revista Produção on line. Florianópolis/SC, Edição Especial, dez., 2007.

BAUMAN, Z. O mal-estar da pós-modernidade. Rio de Janeiro: Jorge Zahar, 1998.

BECK, U. O que é globalização? Equívocos do globalismo: Respostas à globalização. São Paulo: Paz e Terra, 1999.

CASTELLS, M. A sociedade em rede: A era da informação - Economia, sociedade e cultura. São Paulo: Paz e Terra, 1999.

COELHO, S. C. T. Terceiro Setor: um estudo comparado entre Brasil e Estados Unidos. São Paulo: SENAC, 2000.

\section{COHEN, Natan E. O papel do voluntário na}

sociedade moderna. Lisboa: Fundo de Cultura, 1964.

DOHME, Vânia D’ Angelo. Voluntariado - equipes produtivas: como liderar ou fazer parte de uma delas. São Paulo: Mackenzie, 2001.

DOMENEGHETTI, Ana Maria. Definição, tipificação e implantação do setor de voluntários. In: PEREZ, Clotilde; JUNQUEIRA, Luciano Prates (Org.). Voluntariado e a gestão das políticas sociais. São Paulo: Futura, 2002. 
EVANGELISTA, Douglas. Voluntariado e desenvolvimento social. In: PEREZ, Clotilde; JUNQUEIRA, Luciano

Prates (Org.). Voluntariado e a gestão das políticas sociais. São Paulo: Futura, 2002.

GARAY, A. B. S. Voluntariado empresarial: modismo ou elemento estratégico? In: XXV Encontro da Associação Nacional dos Programas de Pós-Graduação em Administração - ENANPAD. 2001, Campinas/SP.

Anais... Campinas/SP: ANPAD, 2001.

\section{GEE, A. The British Volunteer Movement 1794-}

1814. Oxford: Clarendon Press, 2003.

GRATELL, V. A. C. Robert Owen: report to the county of lanark - a new view of society. Middlesex (Reino Unido): Penguin Books, 1970.

HARVEY, D. Condição Pós-Moderna: Uma pesquisa sobre as origens da mudança cultural. São Paulo: Loyola, 1993.

HEDLEY, R; SMITH, J. D. Volunteering \& Society: principles and practice. Londres: Bedford Square Press, 1992.

HUDSON, Mike. Administrando organizações do terceiro setor: o desafio de administrar sem receita. São Paulo: Makron Books, 1999.

KONDO, Y. Motivação humana. 3. ed. São Paulo: Gente, 1989.

MARX, Karl. O capital: o processo de produção do capital. 11. ed. São Paulo: Difel, 1987. (livro 1, v. 1)

Manuscritos econômicos e filosóficos. In:

FROMM, Eric. Conceito marxista do homem. 8. ed. Rio de Janeiro: Zahar Editores, 1983.

MAXIMIANO, Antonio César Amaru. Introdução à administração. 4. ed. São Paulo: Atlas, 1995.

McCURLEY, S.; LYNCH, R. Essencial volunteer management. 2. ed. Londres: The Directory of Social Change, 1998.

MOSTYN, B. The meaning of volunteer work: a qualitative investigation. In: HATCH, S. (Org.)

Volunteers: patterns, meanings \& motives. Hertz (Reino Unido): The Volunteer Centre, 1993.
PORTAL do voluntário. [2006]. Disponível em: < http:// www.portaldovoluntario.org.br/site/pagina.php?idclipping $=3286 \&$ idmenu $=62>$. Acesso em: 3 jul. 2006 .

RAMOS, A. G. A nova ciência das organizações: uma reconceituação da riqueza das nações. 2. ed. Rio de Janeiro: FGV, 1989.

RIFKIN, J. O fim dos empregos: O declínio inevitável dos níveis dos empregos e a redução da força global de trabalho. São Paulo: Makron Books, 1995.

SCHAFF, A. A sociedade informática: As conseqüências sociais da segunda revolução industrial. São Paulo: Brasiliense, 1995.

SENNET, R. A corrosão do caráter: conseqüências pessoais do trabalho no novo capitalismo. Rio de Janeiro: Record, 1999.

SERVA, M. A racionalidade substantiva demonstrada na prática administrativa. Revista de Administração de Empresas, São Paulo, v. 37, n. 2, p. 18-30, 1997.

TEODÓSIO, Armindo dos Santos de Sousa. Programas de incentivo ao voluntariado: novos desafios para a ética gerencial. In: IV Congreso Latinoamericano de Ética, Negocios y Economia. 2001, Buenos Aires. Anais... Buenos Aires: Associação Latinoamericana de Ética, Negócios e Economia/Universidade Argentina de la Empresa, 26-27 de julho de 2001, p. 17-27.

TEODÓSIO, Armindo dos Santos de Sousa. Voluntariado: entre a utopia e a realidade da mudança social. In: Encontro da Associação Nacional dos Programas de Pós-Graduação em Administração - ENANPAD. 2002, Salvador. Anais... Salvador/BA: ANPAD, 2002.

VIDAL, F. A. B. et al. Gestão participativa e voluntariado? Sinais de uma racionalidade substantiva na administração de organizações do terceiro setor. In: XXVIII Encontro da Associação Nacional dos Programas de Pós-Graduação em Administração - ENANPAD. 2004, Curitiba. Anais... Curitiba/PR: ANPAD, 2004.

WUTHNOW, Robert. Between states and markets: the voluntary sector in comparative perspective. Nova Jersey: Princeton University Press, 1991. 